\title{
PENGGUNAAN APLIKASI FIGMA DALAM MEMBANGUN UI/UX YANG INTERAKTIF PADA PROGRAM STUDI TEKNIK INFORMATIKA STMIK TASIKMALAYA
}

\author{
Rully Pramudita ${ }^{1}$, Rita Wahyuni Arifin ${ }^{2}$, Ari Nurul Alfian ${ }^{3}$, Nadya Safitri ${ }^{4}$, Shilka \\ Dina Anwariya 5 \\ Universitas Bina Insani \\ Manajemen Informatika ${ }^{1,2,3,5}$, Rekayasa Perangkat Lunak ${ }^{4}$, Fakultas Informatika, \\ Universitas Bina Insani \\ rullypramudita@binainsani.ac.id 1 , ritawahyuni@binainsani.ac.id ${ }^{2}$, \\ $\underline{\text { arin@ binainsani.ac.id }}^{3}$, nadyasafitri@binainsani.ac.id ${ }^{4}$, shilkadina@gmail.com 5
}

\begin{abstract}
Abstrak
Keberadaan UserInterface (UI) dan User Experience (UX) Designer semakin dibutuhkan beberapa waktu belakangan. Salah satu alasannya karena banyak perusahaan yang mulai menggunakan platform mobile dan situs untuk perkembangan bisnis. Dalam menjawab tantangan ini maka pengetahuan mengenai UI/ UX diperlukan dalam hal melakukan perancangan program, hal ini pun sejalan dengan salah satu tujuan dari profil Prodi S1 Teknik Informatika STMIK Tasikmalaya yaitu; Menghasilkan tenaga ahli di bidang Teknik Informatika yang unggul, terampil menggunakan TIK serta memiliki pengetahuan pendukung yang relevan dengan jenis pekerjaan yang ditanganinya. Kemampuan penguasaaan teknologi dan informasi khususnya kepada mahasiswa semester 3 dari Program Studi Teknik Informatika dalam penguasaan konsep desain UI/UX sangat diperlukan. Melalui kegiatan PkM yang dilaksanakan secara online melalui zoom meeting dan live www.youtube.com, dan diperoleh hasil melalui kuesioner respon balik dari peserta mengenai tingkat kepuasan sebanyak 50\% merasa puas, 38,1\% merasa puas sekali, dan 11,9\% merasa cukup puas dengan adanya PkM ini. Dengan demikian diharapkan mahasiswa dapat meningkatkan wawasan dan kompetensi untuk dapat bersaing pada masa indutri 4.0 ini.
\end{abstract}

Kata kunci-figma, pengabdian masyarakat, ui/ux, user experience, user interface.

\begin{abstract}
The existence of UserInterface (UI) and User Experience (UX) Designer has been increasingly needed in recent times. One of the reasons is because many companies are starting to use mobile platforms and websites for business development. In answering this challenge, knowledge of UI / $U X$ is needed in terms of conducting program design, this is also in line with one of the goals of the S1 Informatics Engineering Study Program profile, STMIK Tasikmalaya, namely; Producing experts in the field of Information Technology who are superior, skilled in using ICT and have supporting knowledge that is relevant to the type of work they handle. The ability to control technology and information, especially for 3rd semester students of the Informatics Engineering Study Program, in mastering the UI / UX design concept is needed. Through PkM activities carried out online through zoom meetings and live www.youtube.com, and results were obtained through questionnaire responses from participants regarding the satisfaction level of $50 \%$ being satisfied, $38.1 \%$ very satisfied, and $11.9 \%$ feeling quite satisfied
\end{abstract}


Rully Pramudita, Rita Wahyuni Arifin, Ari Nurul Alfian, Nadya Safitri, Shilka Dina

Anwariya

Vol. 3 No 1, Februari 2021

ISSN 2657-0203

e-ISSN 2686-0244

with this PkM. Thus, it is hoped that students can increase their insight and competence to be able to compete in this industrial era 4.0.

Keywords - community service, figma, ui/ux, user experience, user interface.

\section{PENDAHULUAN}

Di era modernisasi seperti sekarang, manusia sangat bergantung pada teknologi. Hal ini membuat teknologi menjadi kebutuhan dasar setiap orang. Dari orang tua hingga anak muda, para ahli hingga orang awam pun menggunakan teknologi dalam berbagai aspek kehidupannya. Teknologi di masa kini telah berkembang dengan pesat. Tak seperti waktu dulu, Teknologi sangatlah berpengaruh dalam aspek kehidupan manusia dan ikut berperan dalam kehidupan masyarakat luas khususnya peran teknologi di bidang pendidikan. Dalam pendidikan sendiri teknologi kini memiliki peranan tersendiri dalam proses belajar mengajar (Muhyidin et al., 2020)

Bagi yang tengah belajar desain aplikasi web ataupun mobile kiranya harus tahu apa itu UI (User Interface) dan UX (User Experience). Banyak yang beranggapan bahwa UI dan UX sebenarnya satu karena memiliki tugas yang sama, padahal UI dan UX berbeda satu dengan yang lainnya (Iyan, Agung and Iqbal, 2019).

Dalam melakukan desain suatu tampilan baik untuk berbasis website ataupun mobile memerlukan komunikasi diantara semua tim sehingga tidak terjadi yang namanya redesign. Hal tersebut biasa terjadi kalau tak ada komunikasi visual antar tim designer dan pengembangan tentang rancangan desain aplikasi. Untuk meminimalisir semua kemungkinan yang akan terjadi terutama masalah seperti di atas, buatlah terlebih dahulu rancangan desain dari aplikasi yang ingin dikembangkan. Dengan menggunakan tools yang tersebar cukup banyak di internet baik itu yang gratis maupun berbayar. Salah satunya adalah aplikasi berbasis web adalah Figma. Figma bisa menghemat waktu untuk melakukan verifikasi desain karena kita bisa berkolaborasi seperti memberi komentar, saran, bahkan mengubah rancangan desain yang ada dalam waktu yang bersamaan. Figma adalah aplikasi desain berbasis cloud dan alat prototyping untuk proyek digital. Figma dibuat untuk dapat membantu para penggunanya agar bisa berkolaborasi dalam proyek dan bekerja dalam bentuk tim sekaligus di mana saja. Penulis Nurdin dalam tesisnya membuat desain aplikasi berbasis website menggunakan Figma untuk menggambar User Interface. perancangan sistem ini diharapkan dapat membantu dalam membuat sistem yang efektif dan efisien 
Rully Pramudita, Rita Wahyuni Arifin, Ari Nurul Alfian, Nadya Safitri, Shilka Dina

Anwariya

Vol. 3 No 1, Februari 2021

ISSN 2657-0203

e-ISSN 2686-0244

dalam menunjang aktifitas pada salon mobil. Kata kunci: perancangan, salon mobil, figma Perkembangan otomotif di setiap tahunnya sangat pesat, Karena kondisi cuaca di Indonesia setiap tahunnya tidak mendukung. Dengan melihat perkembangan teknologi saat ini, menjadi hal pokok bagi pebisnis untuk meningkatkan pelayanan kepada konsumen untuk memberikan kemudahankemudahan dalam mendapatkan informasi. Penulis membuat desain aplikasi berbasis website menggunakan Figma untuk menggambar User Interface. perancangan sistem ini diharapkan dapat membantu dalam membuat sistem yang efektif dan efisien dalam menunjang aktifitas pada salon mobil (Nurdin, 2020).

Penulis lain Suryaningsih, dkk pun melakukan penelitian yang menggunakan aplikasi FIGMA dalam perancangan Aplikasi Wakaf Indonesia Berbasis Blockchain Dalam prose pembangunan aplikasi dalam bidang design, software yang dipakai adalah Adobe Photoshop dan Figma. Adobe Photoshop digunakan dalam membuat icon - icon yang dibutuhkan. Figma adalah salah satu aplikasi yang digunakan oleh UI atau UX designer dalam membuat tampilan antarmuka untuk website ataupun mobile apps. Berbeda dengan Adobe Photoshop, aplikasi Figma memudahkan beberapa designer untuk berkolaborasi dan bekerja tim secara

bersama dalam dokumen yang sama serta dapat memberikan komentar, saran, bahkan mengubah rancangan desain yang ada dalam waktu yang bersamaan. Selain itu juga Figma bersifat real time dimana setiap perubahan akan tersimpan secara otomatis (Suryaningsih et al., 2020).

\section{Permasalahan Mitra}

Adapun permasalahan pada mitra, yaitu: Program Studi S1 Teknik Informatika STMIK Tasikmalaya adalah: kurangnya pengetahuan mengenai pengenalan aplikasi FIGMA yang digunakan dalam membangun tampilan antarmuka (user interface) dan user experience (UX) yang interaktif. terhadap peserta terutama mahasiswa semester 3 yang ada pada Program Studi S1 Teknik Informatika

STMIK Tasikmalaya, sehingga mengakibatkan kurangnya pengetahuan dan keterampilan mengenai aplikasi FIGMA.

\section{METODE}

Solusi dari permasalahan yang ada pada Program Studi Teknik Informatika STMIK Tasikmalaya adalah: 1) Mengadakan pelatihan Penggunaan Aplikasi Figma dalam Membangun UI/UX yang Interaktif bagi peserta terutama mahasiswa semester 3 dalam bentuk pengabdian kepada masyarakat. 2) Pembuatan modul praktek untuk penggunaan aplikasi Figma sebagai 
Rully Pramudita, Rita Wahyuni Arifin, Ari Nurul Alfian, Nadya Safitri, Shilka Dina

Anwariya

Vol. 3 No 1, Februari 2021

ISSN 2657-0203

e-ISSN 2686-0244

alat untuk membuat desain UI/UX yang

interaktif, sehingga peserta dapat langsung

mempraktekkan penggunaan Figma.

Metode pelaksanaan PkM dilakukan

dengan cara memberikan pelatihan dan

demonstrasi kepada peserta pelatihan untuk

menggunakan Figma dengan dukungan

media online Zoom meeting https://zoom.us

dan

https://www.youtube.com/watch?v=51B00 ic6UrU.

Evaluasi diberikan kepada peserta pelatihan sebagai umpan balik terhadap PkM yang telah dilakukan dengan menggunakan 5 kisaran nilai: Sangat Baik, Baik, Cukup, Kurang, Kurang Sekali. Kuesioner evaluasi sebagai umpan balik berisi sepuluh

pertanyaan, perhitungan prosentase penilaian menggunakan skala Likert dengan penilaian sangat positif sampai dengan sangat negatif, berupa pemilihan kata dan diberi skor (Sugiyono, 2013):

Kemudian dari hasil kuesioner yang diperoleh dari respon peserta, dilakukan perhitungan menggunakan rumus sehingga dapat diukur dari hasil kegiatan PkM yang diperoleh dari skor jawaban responden (Kusuma, Noviasari and Marthasari, 2016).

\section{HASIL DAN PEMBAHASAN}

PkM dilaksanakan pada hari Sabtu tanggal 15 Januari 2021 yang bertempat di kediaman masing-masing peserta. Pelaksanaan PkM dipandu oleh satu orang pembawa acara, satu orang moderator, satu orang sebagai narasumber, dan dua orang techinal support. Saudari Shilka Dina Anwariya selaku pembawa acara membuka kegiatan PkM pada pukul 14.45 WIB, dilanjutkan dengan menyanyikan Lagu Indonesia Raya dan Hymne Universitas Bina Insani, sambutan Ketua LPPM Universitas Bina Insani Ibu Kristiana Widiawati, S.Pd., M.M, sambutan Ketua Jurusan Teknik Informatika STMIK Tasikmalaya Dani Rohpandi, S. Kom., M. Kom.

Kegiatan inti pelatihan penggunaan Figma untuk pembuatan UI/UX interaktif dimulai pada pukul 15.00 WIB sampai dengan pukul 17.00 WIB, secara interaktif dipandu moderator Rita Wahyuni Arifin, S.Kom., M.Kom bersama narasumber Rully Pramudita, S.T., M.Kom. Narasumber menjelaskan bagaimana cara cara membuat desain UI/UX yang menarik menggunakan Figma, peserta diberikan panduan berupa modul yang berisi langkah-langkah mulai dari : 1) Pengenalan UI/UX, 2) Pengenalan Figma, 3) Cara membuat akun di Figma, 4) Cara menggunakan Figma, seperti membuat file baru di figma, membuat 
Rully Pramudita, Rita Wahyuni Arifin, Ari Nurul Alfian, Nadya Safitri, Shilka Dina

Anwariya

Vol. 3 No 1, Februari 2021

ISSN 2657-0203

e-ISSN 2686-0244

frame, membuat objek, memilih warna,

Umpan balik sebanyak 10 pertanyaan yang dan bagaimana membuat prototipe.

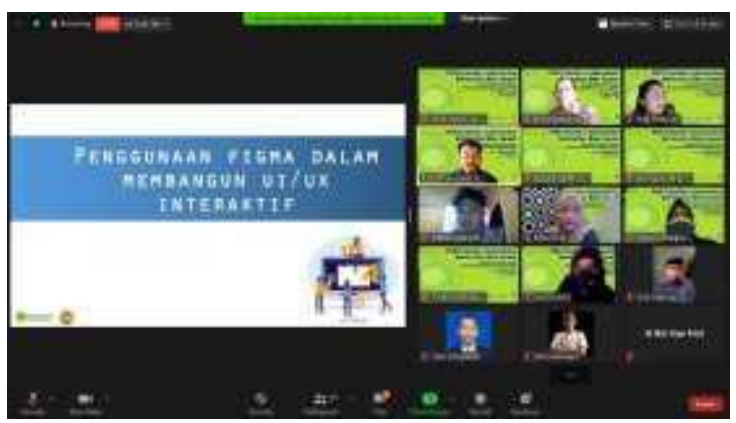

Gambar 1. Materi dalam Pelaksanaan Kegiatan PkM

Dengan selesainya pemaparan materi PkM pada pukul 17.00 WIB oleh narasumber, maka untuk mengetahui kebermanfaatan dari kegiatan yang telah dilaksanakan peserta mengisi umpan balik pengisian melalui kuesioner diperoleh sebanyak 42 peserta, yang sebelumnya melakukan berisi: 1) Materi yang disampaikan dalam Pengabdian Masyarakat, 2) Respon masyarakat terhadap materi yang disampaikan, 3) Hubungan materi yang disajikan dengan kebutuhan Masyarakat,

4) Keterkaitan antara materi dengan aplikasi yang dapat diserap di Masyarakat,

5) Keterkaitan materi dengan kebutuhan,

6) Pemateri dan teknik penyajian, 7) Waktu yang dipergunakan dalam pemberian materi, 8) Kejelasan materi, 9) Minat masyarakat terhadap kegiatan, dan

10) Kepuasan kegiatan. Gambar 2 menunjukkan hasil umpan balik dari peserta untuk tingkat kepuasan dari 42 peserta.

pengisian daftar hadir pada link http://bit.ly/absensipkmfigma .

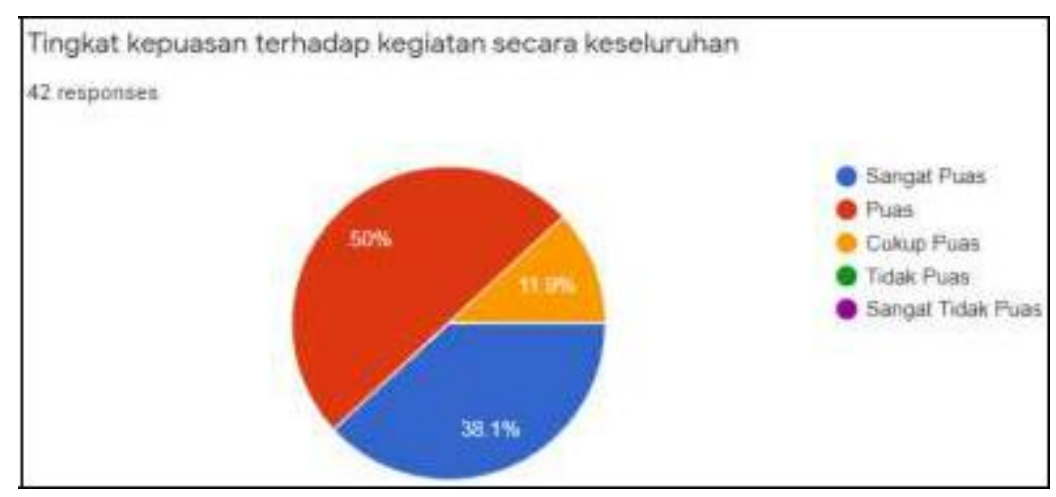

Gambar 2. Hasil Tingkat Kepuasan Peserta

Ucapan terima kasih kepada Program

Studi Teknik Informatika STMIK Tasikmalaya, sehingga PkM ini dapat terlaksana, serta narasumber dan seluruh civitas akademika Universitas Bina Insani yang telah berpartisipasi.

\section{KESIMPULAN DAN SARAN}

Dengan diadakannya kegiatan PkM ini dapat memberikan tambahan wawasan dan pemahaman mengenai penggunaan Figma dalam membuat desain UI/UX yang interaktif bagi mahasiswa dalam 
Rully Pramudita, Rita Wahyuni Arifin, Ari Nurul Alfian, Nadya Safitri, Shilka Dina

Anwariya

Vol. 3 No 1, Februari 2021

ISSN 2657-0203

e-ISSN 2686-0244

mengembangkan minat dan bakatnya.

kegiatan pelatihan. Semoga kegiatan PkM

Berdasarkan hasil Evaluasi umpan balik yang diperoleh dari peserta berdasarkan pertanyaan materi yang disampaikan oleh narasumber hasilnya adalah $59,5 \%$ yang memberikan respon baik sekali, hasil pertanyaan respon peserta terhadap materi yang disampaikan sebesar $59.5 \%$ baik, hasil pertanyaan hubungan materi yang disajikan dengan kebutuhan peserta sebesar $52.4 \%$ baik sekali, hasil pertanyaan keterkaitan antara materi dengan aplikasi yang dapat diserap oleh peserta sebesar $50 \%$ baik sekali, hasil pertanyaan keterkaitan materi dengan kebutuhan sebesar $45.2 \%$ baik sekali, hasil pertanyaan teknik penyajian pemateri sebesar $54.8 \%$ baik sekali, hasil pertanyaan waktu yang digunakan oleh pemateri sebesar $50 \%$ memberi respon baik, hasil pertanyaan kejelasan materi sebesar $42.9 \%$ sangat jelas, hasil pertanyaan minat peserta sebesar $50 \%$ baik, dan tingkat kepuasan secara keseluruhan sebear 50\% memberi respon puas terhadap ini dapat bermanfaat.

\section{DAFTAR PUSTAKA}

Iyan, M., Agung, P. and Iqbal, M. (2019) Desain Grafis dan Multimedia. 1st edn. Bogor: LPPM Universitas Pakuan.

Kusuma, W. A., Noviasari, V. and Marthasari, G. I. (2016) 'Analisis Usability dalam User Experience pada Sistem KRS Online UMM menggunakan USE Questionnaire', Jurnal Nasional Teknik Elektro dan Teknologi Informasi (JNTETI), 5(4), pp. 294-301. doi: 10.22146/jnteti.v5i4.277.

Muhyidin, M. A. et al. (2020) 'Perancangan Ui / Ux Aplikasi My Cic Layanan Informasi Akademik Mahasiswa', 10(2), pp. 208-219.

Nurdin, A. A. (2020) Analisa Dan Perancangan Salon Cuci Mobil Berbasis Web (Studi Kasus: Excellent Car Wash \& Ceramic Coating). Universitas Mercubuana.

Sugiyono (2013) Metode Penelitian Kuantitatif, Kualitatif dan $R \& D$. Bandung: Alfabeta.

Suryaningsih, S. et al. (2020) 'Aplikasi Wakaf Indonesia Berbasis Blockchain', Edumatic: Jurnal Pendidikan Informatika, 4(2), pp. 2029. doi: 10.29408/edumatic.v4i2.2402. 